\title{
Losing your livelihood just twenty minutes from now
}

How would you feel if you had just been diagnosed with a lifealtering or threatening condition? Understandably, you would probably be fairly distressed.

What if you were then told in the next breath that by law you had to stop practising dentistry immediately and for good? Distressed or beside yourself with despair as you begin to realise what will happen to you and your dependents, how would you then feel to be told that there is no evidence-base to support this ruling? Obscure plot in a novel? Nightmare scenario? No, it actually happens right here in the UK.

The opinion piece in this issue, Written off (pages 497-499), describes the somewhat unbelievable, but true situation of UK dental colleagues who are diagnosed as HIV positive and who have to instantly give up practice. The current guidance from the United Kingdom Advisory Panel (UKAP) advising on infected healthcare workers requires a cessation of effectively all aspects of contemporary clinical dental practice as soon as the infection is diagnosed and it is worth realising that a preliminary diagnosis is now available in just 20 minutes using a saliva test. Apart from examination using no sharp instruments, the taking of certain radiographs, recording of impressions of an edentulous mouth and the fitting of full dentures, all other dentistry is off limits from that moment on. Everything else is regarded as an 'exposure prone procedure', which is based on the operator's inability to see the end of any instrument that is in use at anytime during the procedure.

For the affected colleague there is no time to finish a course of treatment, plan their future in any measured way or attend to matters of practice business. It is the dental practice equivalent of clearing your desk and being escorted off the premises.

It is now some years since the guidance was reviewed and clearly it is time to do that. No other country in the industrialised world has such draconian measures in place. In the USA and Canada, for example, HIV positive dentists can continue as normal once their viral levels are controlled and with the one additional proviso that they must adopt universal precautions and recommended infection control procedures. This is perhaps surprising, given the USA's predilection for litigation and yet there is no evidence at all (with the one famous exception and still as yet unexplained case in 1990 in America) of HIV transmission from a dentist to a patient during dental treatment.

But if the lack of up-to-date evidence base applies to the situation of the individual dentist, or dental care professional, then what can only be described as the emotional response also extends to other organisations such as Primary Care Trusts and government agencies. 'Look back exercises' as they are called, seek out (former) patients of practitioners and provide HIV testing and appropriate counselling. As a knee jerk reaction this might seem logical and a reassurance to the patients in particular and the public in general. When such situations first arose there may well have been a justification but surely we need to learn from science and from history if we regard ourselves as any kind of profession guided by science? The plain truth is that not a single look back exercise in the UK has ever found any evidence of HIV transmission from a dentist to a patient. The amount of distress, anxiety and sleepless nights created in those concerned has not been measured and can hardly even be imagined. It must be time to fundamentally review this aspect of policy as well.

We should also ask about our own emotional response. To what extent do we as a profession regard colleagues who are HIV positive? We must not forget that we are a caring profession and it is a duty of care that should extend to our colleagues as well as our patients. Once UKAP has changed its guidance, as it must surely now do, we will need to consider what further professional support we must put in place for colleagues allowed to practice again.

There may well have been good reasons for the initial creation of the guidelines, policies and philosophies at the time when HIV first struck and we were struggling to understand its mode of transmission, aetiology, the conditions it caused and the consequences. Some may remember the government adverts with the 'AIDS tombstone' as being perhaps one of the most graphic public health images of the late 1980s. But there seem few good reasons, if any, for the measures that are still current to remain in place any longer given the huge leaps that we have made in our knowledge. We know that universal cross-infection procedures work, we know that the modern drug armamentarium provides effective treatment, we know that HIV positive dentists can continue to treat patients safely and as well as before being diagnosed. It must be time for the Department of Health to reconvene UKAP and charge them to reassess current evidence and practice.

Stephen Hancocks OBE, Editor-in-Chief doi: 10.1038/sj.bdj.4814161 